\title{
Estado y movimiento indígena en el Ecuador: Del multiculturalismo neoliberal al Estado plurinacional degradado*
}

\author{
Fernando Larrea Maldonado*
}

\begin{abstract}
Resumen

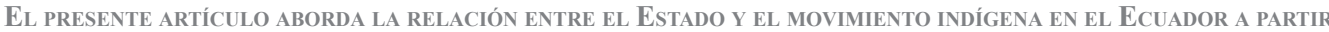

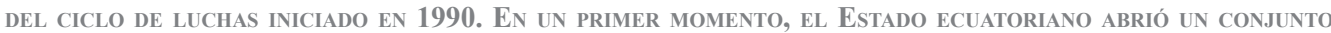
DE ESPACIOS Y CONCESIONES FRENTE A LAS DEMANDAS INDIAS EN EL MARCO DE UNA POLÍTICA MULTICULTURALISTA

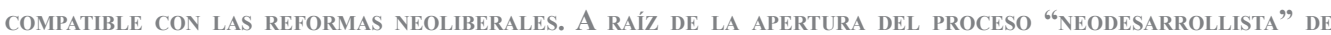
LOS ÚlTimos AÑos, EL ESTAdo ECUATORIANO DESPLEGÓ NUEVAS MODALIDAdES DE ADMINISTRACIÓN DE LA CUESTIÓN INDÍGENA QUE MODIFICAN NEGATIVAMENTE EL SENTIDO DEL RECONOCIMIENTO CONSTITUCIONAL DEL ECUAdOR COMO Estado pluRinaCional. Estas políticas degradan los SENTIDOS Y CONTENIDOS DE La PLURINACionalidad DEFENDIDA POR EL MOVIMIENTO INDÍGENA EN LO QUE SE REFIERE A LA ORGANIZACIÓN INDÍGENA Y SU CUALIDAD DE SUJETO POLítico, ASí COMO A LA AUTONOMÍA Y A LA AUTODETERMinACIÓN DE PUEBLOS Y NACIONALIDAdES. ESTE PROCESO HA ABIERTO UN NUEVO CAMPO RELACIONAL DE COERCIÓN Y RESISTENCIAS.
\end{abstract}

Palabras Claves: Movimiento indígena - multiculturalismo - neoliberalismo - Estado Plurinacional.

Abstract

The present article deals with the relationship between the STate and the indigenous movement in Ecuador since the cyCle of Struggles began in 1990. At First, the ECUAdorian STATE OPENEd a set of SPACES AND GAVE CONCESSIONS IN RESPONSE TO THE INDIGENOUS DEMANDS IN THE FRAMEWORK OF A MULTICULTURALIST POLICY COMPATIBLE WITH NEOLIBERAL REFORMS. AS A RESULT OF THE OPENING UP OF THE NEODESARROLLISTA PROCESS OF RECENT YEARS, THE ECUADORIAN STATE HAS DEPLOYED NEW WAYS TO ADMINISTRATE INDIGENOUS AFFAIRS WHICH

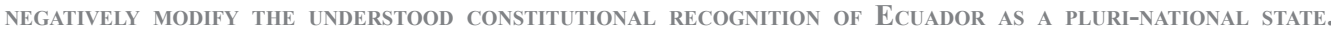
THESE POLICIES DEGRADE THE CONCEPT OF PLURI-NATIONALITY DEFENDED BY THE INDIGENOUS MOVEMENT, REFERRING TO INDIGENOUS ORGANIZATION AND ITS CAPACITY AS A POLITICAL ACTOR, AS WELL AS ERODING THE AUTONOMY AND

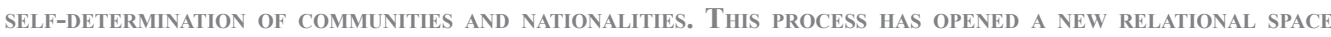
BETWEEN COERCION AND RESISTANCE.

KEYWORDS: INDIGENOUS MOVEMENT - MULTICULTURALISM - NEOLIBERALISM - PLURI-NATIONAL STATE.

* Este artículo es una versión adaptada de la ponencia con el mismo título, presentada al III Congreso Latinoamericano y Caribeño de Ciencias Sociales, FLACSO, Quito, Agosto 2015.

** Doctorado del Programa de Pós-Graduação em Ciências Sociais da Universidade Federal da Bahia (PPGCS - UFBA) y becario de la Fundação de Amparo à Pesquisa do Estado da Bahia (FAPESB). Correo electrónico: ferlarrea@gmail.com 


\section{Introducción}

$\mathrm{E}$ n América del Sur, los procesos políticos protagonizados por los movimientos indígenas de Ecuador y de Bolivia constituyen los casos más emblemáticos de las luchas, conquistas y transformaciones alcanzadas por los movimientos indígenas y campesinos en su relación con los Estados Nacionales. En el Ecuador, las luchas levantadas por el movimiento indígena se convirtieron en un referente de los procesos de resistencia al neoliberalismo durante la década del 90 del siglo pasado y los primeros años del siglo XXI. Como consecuencia de profundas crisis políticas y de las propias demandas del movimiento, se abrieron espacios para el reconocimiento constitucional de derechos colectivos de los pueblos y nacionalidades indígenas, primero en la Constitución de 1998 y posteriormente en la Constitución actualmente vigente, promulgada en el 2008, en la cual se reconoce el carácter plurinacional e intercultural del Estado ecuatoriano y un amplio abanico de derechos colectivos a las comunidades, pueblos y nacionalidades indígenas.

Luego del reconocimiento constitucional de los derechos colectivos indígenas y del carácter plurinacional del Estado que durante varios años había sido una de las mayores aspiraciones del movimiento indígena, en el gobierno de Rafael Correa se verifica un progresivo incremento de las tensiones, conflictos y discrepancias entre este gobierno y algunas de las más importantes organizaciones indígenas. Son múltiples los ejemplos recientes de los conflictos entre las políticas, propuestas, leyes y decretos implantados por el gobierno y la defensa por parte de las organizaciones indígenas de sus derechos y de sus territorios, aun cuando el presidente y otros representantes de su gobierno hayan incorporado en su discurso político una retórica anti-neoliberal y varios elementos simbólicos y políticos levantados por el propio movimiento indígena en sus luchas, tales como el sumak kawsay (buen vivir) o el respeto a la "Pachamama".

El presente trabajo aborda la relación entre el Estado y el movimiento indígena en el Ecuador a partir del ciclo de luchas iniciado desde el primer levantamiento indígena nacional en 1990. Argumenta que frente a la irrupción india el Estado ecuatoriano articuló progresivamente una política compatible con las reformas neoliberales que al mismo tiempo que establecía concesiones y abría espacios en la institucionalidad estatal para la participación indígena, conjuraba los peligros implícitos en el proceso de movilización indígena campesina, garantizando así los procesos de acumulación capitalista en el campo. Esta política de administración de la población indígena tuvo como eje articulador la adopción del multiculturalismo como discurso dominante y dispositivo de poder. A raíz de la apertura del proceso "neodesarrollista" de los últimos años, el Estado ecuatoriano desplegó nuevas modalidades de administración de la cuestión indígena que modifican negativamente el sentido del reconocimiento constitucional del Ecuador como Estado plurinacional.

Desde la perspectiva de este trabajo, se entiende que estas políticas degradan los sentidos y contenidos de la plurinacionalidad defendida por el movimiento indígena, particularmente en lo que se refiere a la organización indígena y su cualidad de sujeto político, así como a la autonomía y a la autodeterminación de pueblos y nacionalidades. Este proceso ha abierto un nuevo campo relacional de coerción y resistencias.

\section{El multiculturalismo como dispositivo biopolítico en el Ecuador neoliberal}

En Ecuador, el "Primer levantamiento indígena nacional", protagonizado en junio de 1990, significó la irrupción del movimiento indígena en la arena política con su propia voz y discurso político. Marcó también el inicio de un ciclo de movilizaciones y protestas que se extendería durante toda la década del 90 y que solo declinaría temporalmente luego del levantamiento indígena de enero del 2001, convocado en rechazo a las medidas de ajuste económico tomadas durante el gobierno de Gustavo Noboa. Al calor de este ciclo de 
movilizaciones el movimiento indígena' ${ }^{1}$ se constituyó en el principal movimiento social en el país, condensando en torno a sí las luchas de resistencia a la aplicación de las políticas neoliberales y de ajuste estructural de la economía.

La irrupción del movimiento indígena en la arena política nacional colocó a la cuestión étnica en el debate nacional y en el centro de la relación entre el movimiento indígena y el Estado. Al situar como un punto nodal en sus demandas el reconocimiento constitucional del Ecuador como un Estado plurinacional e intercultural y los derechos colectivos de los pueblos y nacionalidades indígenas, confrontó los fundamentos de la estructuración política del Estado ecuatoriano. Al mismo tiempo, durante todo el ciclo de protestas, las demandas étnicas vinculadas al planteamiento de la plurinacionalidad estuvieron fusionadas con reivindicaciones clasistas como la lucha por la tierra y por territorios, el acceso al agua o, en términos más amplios, contra las medidas económicas neoliberales asumidas por distintos gobiernos en un contexto de crisis política y de agudización de la crisis económica (1999-2000).

El Estado ecuatoriano no fue inmune a este ciclo de luchas indígenas. A partir de la irrupción del movimiento indígena como un nuevo agente en el escenario político nacional en los años 90, el Estado redefinió su relación con los indígenas (no sin tropiezos y conflictos), articulando progresivamente a través de distintos mecanismos una política neoindigenista, coherente y compatible con el neoliberalismo, política que incorporó la participación de representantes indígenas en su gestión. Esta política puede ser entendida como una nueva modalidad de "administración de poblaciones"2 (Guerrero, 2010), como una biopolítica (Foucault, 2001) que toma como sujeto y objeto de la misma a la población indígena y que tiene como uno de sus ejes la adopción por parte del Estado de un multiculturalismo adecuado con las reformas neoliberales.

Esta política permitió al Estado ecuatoriano procesar las demandas indígenas, establecer algunas concesiones y abrir espacios en la institucionalidad estatal para la participación indígena, al mismo tiempo que garantizaba los procesos de acumulación capitalista en el campo. Paralelamente, como resultado de este proceso de interacción con el Estado y de la incorporación de la participación de representantes indígenas en la gestión de esta política, se produjo un progresivo desmontaje de contenidos contestatarios presentes en el discurso ${ }^{3}$

1 En este trabajo me refiero al movimiento indígena ecuatoriano en un sentido amplio, constituido desde sus múltiples expresiones político organizativas de nivel nacional: la Confederación de Nacionalidades Indígenas del Ecuador (CONAIE) y sus filiales regionales (Confederación de Nacionalidades Indígenas de la Amazonía Ecuatoriana CONFENIAE; Confederación Kichwa del Ecuador - ECUARUNARI; y, Confederación de Nacionalidades Indígenas de la Costa Ecuatoriana CONAICE); la Confederación de Organizaciones Campesinas, Indígenas y Negras (FENOCIN); la Federación Ecuatoriana de Indígenas Evangélicos (FEINE); y, la Federación Ecuatoriana de Indios (FEI). Estas organizaciones que en términos generales estructuran al movimiento indígena ecuatoriano expresan diversas tendencias e intereses frente a las políticas del Estado ecuatoriano, confluyendo en algunas ocasiones en sus posicionamientos e incluso en sus acciones o divergiendo y estableciendo posiciones contrapuestas en otras.

2 Andrés Guerrero utiliza el concepto de "administración de poblaciones" para caracterizar al sistema de dominación étnica implantado en el país a partir de 1857 (Guerrero, 2000; 2010). Para este autor, a partir de 1857, año en que el parlamento aprobó la igualación legal de los indígenas al resto de ecuatorianos, se produce "un cambio en el sistema de dominación": desde una "modalidad explícita de gestión, concentrada en las instituciones del Estado", a una forma republicana, en la cual "se configura un campo ciudadano de ejercicio del poder sobre los indígenas", descentrado del eje público estatal. Para este autor, se trata de la emergencia de una "esfera privada de dominación étnica". A partir de este momento, se implanta una formación de dominación de indígenas "inscrita en el sistema ciudadano: compatible con sus principios y sus leyes" (Ibíd.: 11-12). La administración de poblaciones puede asumir un carácter privado como en el caso analizado por Guerrero o tener un carácter público, como una función atribuida al Estado (Ibíd.: 2010).

3 Entiendo la noción de discurso desde la perspectiva desarrollada por Foucault $(1979 ; 2005)$, esto es en su vínculo directo con las relaciones de poder y con las formas de producción de verdad que una sociedad se da en un momento determinado. En este sentido, la noción de discurso, como un conjunto de enunciados y prácticas asociadas a ellos que forman una unidad, encarna una doble dimensión: como expresión y condensación de las relaciones existentes que determinan lo que puede ser dicho en un momento y contexto determinado y al mismo tempo como un arma que construye y significa la realidad, posiciona a los sujetos sociales e incide en las relaciones de poder. Así, Foucault (2011: 220-221) caracteriza metafóricamente el discurso como una batalla, un operador de las relaciones de fuerza. En el caso del movimiento indígena ecuatoriano, estos dos aspectos son cruciales al momento de entender las condiciones de surgimiento de un discurso político sobre sí mismo que lo constituye como agente político con capacidad de representarse y ser reconocido como interlocutor en la escena pública. Desde esta perspectiva, el discurso del movimiento indígena puede ser analizado como una unidad, más allá de la multiplicidad de contenidos, diferencias, inconsistencias y contradicciones internas. 
del movimiento indígena, transformando las expectativas y el perfil de muchos de sus representantes ${ }^{4}$.

Esta línea de interpretación de las políticas del Estado hacia los indígenas, desplegadas y articuladas como estrategias de conjunto para la administración de la cuestión étnica y la diferencia cultural, se enmarca en una perspectiva teórica que retoma las categorías de gubernamentalidad y biopolítica desarrolladas por Foucault. Este autor desarrolla estas nociones al analizar los mecanismos y dispositivos de poder que surgen en el momento en que la población pasa a ser el objeto y el sujeto del "arte de gobernar". La gubernamentalidad es entendida como "el conjunto constituido por las instituciones, los procedimientos, análisis y reflexiones, los cálculos y las tácticas" que permiten ejercer esta forma de poder "que tiene como meta principal la población, como forma primordial de saber la economía política, como instrumento esencial, los dispositivos de seguridad" (Foucault, 2006: 136).

Se trata entonces de una tecnología de poder que se despliega a partir del siglo XVIII, que toma a la población como meta última y a la vez como instrumento del gobierno y "que aspira no por medio del adiestramiento individual sino del equilibrio global, a algo así como una homeostasis: la seguridad del conjunto con respecto a sus peligros internos" (Foucault, 2001: 225). Así, este concepto está directamente vinculado con las tácticas de gobierno que sirven de base a la formación del Estado moderno.

Para Foucault esta tecnología de poder no suplanta al poder soberano que fundamenta la ley, ni a los dispositivos disciplinarios (analizados en varias de sus obras). Por el contrario, advierte: "De hecho estamos ante un triángulo: soberanía, disciplina y gestión gubernamental, una gestión cuyo blanco principal es la población y cuyos mecanismos esenciales son los dispositivos de seguridad" (Foucault, 2006: 135). Los dispositivos de seguridad se caracterizan por su capacidad de regular la realidad sobre la que actúan: Los fenómenos de orden colectivo que afectan a la población como conjunto. Población considerada a su vez como objeto, el blanco al cual apuntan estos mecanismos para obtener efectos determinados y previsibles; y, como sujeto, en cuanto se le pide que actúe de determinadas maneras (Foucault, 2006).

Con el manejo de la población como sujeto y objeto de las tácticas de gobierno aparecen un conjunto de técnicas o mecanismos de regulación de fenómenos o procesos colectivos que se relacionan con la vida. Estos mecanismos de regulación se aplican a la "vida de los hombres", es decir no sobre los cuerpos individuales (como en el caso del poder disciplinario) sino al hombre como "ser viviente", a la "multiplicidad de hombres" en la medida en que esta multiplicidad forma "una masa global, afectada por procesos de conjunto que son propios de la vida, como el nacimiento, la muerte, la producción, la enfermedad, etcétera" (Foucault, 2001: 220).

Al referirse a estos mecanismos de regularización sobre la vida y los procesos biológicos del hombre/especie, Foucault (2001: 217) introduce el concepto de biopoder o biopolítica, constatando una tendencia conducente a "la estatización de lo biológico". Así, mientras el poder disciplinario opera sobre los sujetos en tanto individuos, en tanto cuerpos y almas, sometiéndolos, adiestrándoles, produciéndolos como "sujetos", el biopoder en cambio opera sobre "la población" como conjunto, sobre el "hombre/especie", regulando la vida en general. De esta manera, Foucault delinea dos series: "cuerpo-organismo-disciplina-instituciones; y la serie población-procesos biológicos-mecanismos regularizadores-Estado" (Ibíd.: 226), que configuran la sociedad de normalización que caracteriza al capitalismo industrial.

4 Estos aspectos se expresaron por ejemplo en la desactivación de las demandas agrarias y la desarticulación de los contenidos clasistas ligadas a ellas en el discurso político de la Confederación de Nacionalidades Indígenas del Ecuador (CONAIE), luego del proceso de negociación de la ley agraria que siguió al levantamiento indígena de 1994. En los años siguientes se consolidaría internamente una tendencia que priorizaba la participación institucional dentro del Estado, con un discurso de afirmación de la diversidad cultural y de los derechos colectivos de los pueblos indígenas. Las demandas agrarias serían retomadas con fuerza solo una década más tarde, a partir de las movilizaciones contra la firma del Tratado de Libre Comercio con Estados Unidos en el 2006. Al respecto ver: Martínez, 2005; Bretón, 2009. 
Desde la línea interpretativa de este trabajo, cabe resaltar la complementariedad que las nociones de gubernamentalidad y biopolítica ofrecen en relación a la concepción de hegemonía de Gramscis para el análisis de los procesos políticos. Así, se puede afirmar que "el arte de gobernar" (al que se refiere en última instancia la noción de gubernamentalidad) constituye precisamente "el arte" de construcción de hegemonía desplegado en las sociedades capitalistas, destinado a administrar minuciosamente a la población, transformando sus comportamientos, percepciones y prácticas, para conjurar los peligros internos. Igualmente, en la medida en que la biopolítica por medio de sus mecanismos regularizadores se traduce en la posibilidad de cualificar la vida, mejorar sus desempeños, incorpora frecuentemente en su lógica el bienestar de los gobernados y "extrae su propia fuerza de la fuerza de sus súbditos", obligando al Estado a generar prestaciones en múltiples ámbitos, desde la defensa, hasta la economía y la salud pública (Esposito, 2006: 60).

De esta forma, las biopolíticas constituyen poderosos instrumentos para la construcción de consenso y legitimación. Para Gramsci (2000: 48), la hegemonía presupone indudablemente que se consideren los intereses y las tendencias de los grupos sobre los cuales se ejerce esta hegemonía (en este sentido extrayendo su propia fuerza de la fuerza de los súbditos), lo cual supone el establecimiento de concesiones para las clases dominadas, en la medida en que no afecten lo "esencial" respecto al núcleo decisivo de la actividad económica en el capitalismo.

Desde esta perspectiva teórica es posible situar las relaciones entre el Estado y el movimiento indígena, operadas desde 1990, en un campo estratégico de relaciones de fuerza que se van tejiendo a partir de un conjunto de condicionamientos históricos en los cuales se inserta la cuestión indígena en el país, de las exigencias del proceso de desarrollo capitalista en su fase neoliberal ${ }^{6} \mathrm{y}$ de la actuación de este movimiento frente al Estado y las clases dominantes. Más allá de las diferencias y definiciones coyunturales presentes en la gestión de uno u otro gobierno en relación a la cuestión étnica, colocar la discusión en términos de las tecnologías de poder, de las tácticas que se despliegan, contribuye a un análisis de las acciones y políticas impulsadas desde el Estado en términos de sus puntos de convergencia, de la coherencia subyacente que van alcanzando en su articulación como estrategias de conjunto, destinadas a administrar, en palabras de Foucault (2006: 194), “en profundidad, con minucia y en sus detalles”, la cuestión étnica y la población indígena, para evitar la amenaza que el movimiento indígena representaba, para el proceso de desarrollo y acumulación capitalista en el campo.

Asimismo, supone la posibilidad de entender la confluencia de estas tácticas, acciones y políticas con otras fuerzas presentes a nivel nacional e internacional, por fuera del marco restrictivo de la institucionalidad del Estado. En este sentido, la adopción por parte del Estado de un multiculturalismo adecuado al neoliberalismo ${ }^{7}$ puede ser considerada como un eficiente

5 Al conjugar la coerción con el consenso en la noción de hegemonía, Gramsci (2002) abrió un terreno fértil de discusión en torno a los mecanismos que permiten que la supremacía de la burguesía en los modernos Estados capitalistas se traduzca y sustente en un consenso activo de las clases dominadas, en su aceptación del orden establecido como un orden natural, permitiendo así la reproducción del sistema capitalista. Gramsci advierte cómo la supremacía de un grupo social se manifiesta tanto como dominio (en el sentido de la coerción y presencia directa o latente del uso de la fuerza) y al mismo tiempo como dirección intelectual y moral en el conjunto de la sociedad (Ibíd.).

6 En este trabajo asumo las contribuciones complementarias de Harvey (2008); Duménil y Lévy (2014); y, Laval y Dardot (2013) sobre el neoliberalismo. Para Duménil y Lévy (2014) el neoliberalismo debe ser comprendido como una nueva fase en la evolución del capitalismo que surgió a raíz de la crisis de la década del 70 y expresa la estrategia de las clases capitalistas de reforzar su hegemonía y expandirla globalmente. Harvey (2008) también considera al neoliberalismo como un proyecto político orientado para el restablecimiento de las condiciones de acumulación del capital y de restauración del poder de las élites económicas. Para Harvey, el Estado neoliberal se encarnó en un aparato de Estado orientado fundamentalmente a crear las condiciones favorables para la acumulación lucrativa del capital por los capitalistas domésticos y extranjeros. El neoliberalismo no tornó irrelevante al Estado, sino que supuso una radical reconfiguración de sus instituciones y sus prácticas. Laval y Dardot (2013: 25) por su parte consideran al neoliberalismo como una racionalidad gubernamental (siguiendo a Foucault), "la razón del capitalismo contemporáneo", que despliega "la lógica del mercado como lógica normativa generalizada, desde el Estado hasta lo más íntimo de la subjetividad", generalizando el principio de la competencia como norma de conducta y tomando a la empresa como modelo de subjetivación.

7 Para una caracterización del "multiculturalismo neoliberal” ver Hale, 2002 y 2005. 
dispositivo de poder/saber y de construcción de hegemonía para la administración de la población indígena, conjurando los peligros internos implícitos en su proceso de movilización y en los cuestionamientos al modelo neoliberal. Al mismo tiempo, esta perspectiva contribuye para la comprensión de las complejas dinámicas del movimiento en el transcurso de las últimas décadas y cómo las respuestas desde el Estado han moldeado sus acciones, reconfigurado sus discursos, adecuando sus dinámicas y sus prácticas de resistencia a las condiciones impuestas por el proceso de desarrollo capitalista en su fase neoliberal.

Desde esta perspectiva, se puede caracterizar cinco ejes principales alrededor de los cuales se concretó esta política de administración de la población indígena:

1. la instrumentalización de mecanismos de diálogo y negociación entre el Estado y el movimiento indígena posteriores a los distintos levantamientos, en el terreno planteado por el Estado, con agendas restringidas que cercaron cualquier posibilidad de revertir las tendencias de aplicación de las políticas neoliberales y el modelo de acumulación capitalista en el campo;

2. el establecimiento de concesiones y el reconocimiento de derechos colectivos y de la plurinacionalidad en la Constitución -enmarcadas en el terreno abonado por el multiculturalismo- con escasa aplicabilidad al depender de la legislación secundaria, sin modificar sustancialmente las condiciones de subordinación indígena, ni afectar aspectos relativos a las relaciones económicas;

3. en el mismo tenor multiculturalista, la generación de un neo-indigenismo de Estado mediante el establecimiento de una institucionalidad indígena ${ }^{8}$ específicamente dedicada a la cuestión indígena y gestionada por los propios representantes indios;

4. la entrega de recursos y la atención a demandas puntuales, en el espacio de confluencia del campo político y del desarrollo rural, con el apoyo de organismos multilaterales y organizaciones no gubernamentales de desarrollo (ONGD) y la subordinación de las organizaciones indígenas a los discursos dominantes en el campo social del desarrollo; $y$,

5. la incorporación activa de las dirigencias y los representantes indígenas en la gestión de espacios abiertos en el aparato del Estado a nivel de ministerios, en las entidades estatales para indígenas, en la gestión de gobiernos locales y de proyectos de desarrollo orientados a esta población.

La aplicación de esta política permitió garantizar la aplicación de medidas neoliberales en el agro, desmontar algunos de los ejes contestatarios y anti-sistema presentes en el movimiento indígena y disminuir progresivamente su capacidad de movilización. Ella se afincó en el reconocimiento explícito de la legitimidad de la participación indígena en la gestión pública, incorporando la participación de algunos de sus "representantes" en distintos puestos e instancias de gobierno, en la medida en que no afectaba la orientación establecida de las políticas públicas. En este sentido, se produjo una re-definición de la formación de dominación étnica, con una participación activa del Estado, que si bien abrió nuevos espacios para los indígenas en el campo político, no alteró sustancialmente las condiciones de subordinación indígena y campesina al proceso de desarrollo capitalista en el país.

Al hacer una revisión de estas políticas y de su surgimiento y consolidación en sucesivos gobiernos, es interesante constatar que ellas tienen como discurso articulador y como justificativa el respeto a la diversidad cultural y un multiculturalismo de Estado que parte del reconocimiento del Ecuador como país pluriétnico, multicultural y posteriormente plurinacional e intercultural.

8 Entre las principales entidades indígenas creadas dentro del Estado se destacan la Dirección Nacional de Educación Intercultural Bilingüe (DINEIB), el Consejo de Desarrollo de las Nacionalidades y Pueblos del Ecuador (CODENPE) y la Dirección de Salud de las Nacionalidades y Pueblos Indígenas adscrita al Ministerio de Salud. 
Cabe resaltar que el discurso del multiculturalismo se desarrolla y adquiere centralidad como discurso dominante a nivel internacional durante las décadas de 1980 y 1990, en un contexto marcado por un nuevo ciclo de acumulación y expansión del capital en escala planetaria, ciclo caracterizado por el predominio de las grandes corporaciones transnacionales y el capital financiero: el momento neoliberal del capitalismo global.

El discurso del multiculturalismo condensa de manera emblemática este giro en las posturas teóricas y políticas para permitir un "adecuado" tratamiento de las diferencias y de la diversidad cultural en el contexto del capitalismo global y de los Estados liberales". Así, se procuraría que en una sociedad diversa los distintos grupos étnicos en cuestión ocupen una posición de igualdad frente al Estado, a partir de un acto de reconocimiento de esta diversidad, tendiente a generar prácticas políticas y redistributivas más incluyentes (Cervone, 2009). Al referirse al reconocimiento de derechos diferenciados en el contexto de una supuesta igualdad ciudadana, el discurso del multiculturalismo concentra la discusión en los aspectos jurídicos y culturales. Deja de lado por lo tanto las dinámicas económicas de la producción capitalista generadoras de desigualdades que generalmente se fusionan con las distinciones étnicas, las cuales inciden directamente sobre los derechos individuales o de grupo. En este sentido, tampoco plantea ningún nivel de relación entre la diferenciación étnica y clasista como elementos estructurantes en los que se asienta la desigualdad.

Desde una mirada crítica a las políticas de la identidad basadas en el discurso del multiculturalismo que acompañaron las reformas neoliberales en muchos países de América Latina, Díaz Polanco (2009) muestra cómo las diferencias culturales dejaron de ser ignoradas o atacadas directamente, para dar pie a una nueva estrategia tendiente a su "disolución gradual mediante la atracción, la seducción y la transformación". Díaz Polanco acuña la noción de etnofagia para calificar esta estrategia por su carácter devorador y asimilador de las identidades étnicas a través de un conjunto de "imanes socioculturales y económicos desplegados para atraer, desarticular y disolver a los grupos diferentes".

Esta estrategia no excluye el objetivo de la integración sino que lo promueve por otros medios, al modelar las diferencias culturales bajo el manto del respeto y la exaltación de los valores indígenas. El Estado se presenta como garante o protector de los valores étnicos a la hora de atenuar los impactos de los procedimientos del capitalismo salvaje. Por otro lado incorpora la participación de representantes de los grupos étnicos para convertirlos en promotores de la integración "por propia voluntad" como ideólogos y agentes de las nuevas prácticas indigenistas (Ibíd.: 158).

El predominio del multiculturalismo como enfoque teórico político supone una concepción sobre la diversidad y cómo tratarla, definiendo así las condiciones en que las identidades pueden ser aceptadas, insertándolas en el sistema de dominación. En este contexto se comprende la adopción de reformas legales que reconocen el carácter plurinacional del Estado y pluricultural de la sociedad y establecen algunos derechos específicos para los pueblos indígenas, mientras al mismo tiempo se adoptan modelos y políticas socio-económicas

9 Charles Taylor (2009) y Will Kymlicka (1996) son los principales referentes teóricos del multiculturalismo, con sus análisis a partir del caso de Canadá. De distintas maneras, estos autores buscan compatibilizar el reconocimiento de derechos específicos y colectivos a poblaciones con identidades culturales diferenciadas, con la universalización de derechos y la noción liberal de ciudadanía en los Estados liberales. Los últimos años distintos autores han planteado posiciones críticas a las políticas de la identidad basadas en el reconocimiento de la diversidad cultural y el multiculturalismo, marcando los límites de esas políticas en un contexto de exacerbación de las desigualdades con la globalización económica y el neoliberalismo (ver: Žižek, 2005; Hale, 2002 y 2005; Díaz Polanco, 2009). Es conocido el debate protagonizado por Nancy Fraser y Axel Honneth en torno a la teoría del reconocimiento (ver: Fraser 2000, 2001 y 2007; Honneth 2003 y 2007, Mattos, 2006). Para Fraser, las demandas por el reconocimiento de las diferencias (nacionalidad, etnicidad, raza, género y sexualidad) levantadas por una variedad de movimientos sociales que cobraron primacía como "forma paradigmática" del conflicto político en el final del siglo XX, centradas en diversas formas de reconocimiento cultural, desplazaron las luchas por la redistribución socioeconómica como objetivo de la lucha política frente a las injusticias (Fraser, 2001, p. 245). 
enmarcadas en el neoliberalismo, que minan directamente la identidad de los pueblos indios desde sus cimientos: las comunidades. De esta forma se delinean y precisan los "límites de la tolerancia" neoliberal hacia lo diferente, buscando que ningún reconocimiento afecte el orden político o el modelo económico. A partir de estos planteamientos Díaz Polanco (2009: 170) concluye: "El multiculturalismo se ocupa de la diversidad en tanto diferencia 'cultural', mientras repudia o deja de lado las diferencias económicas y sociopolíticas que, de aparecer, tendrían como efecto marcar la disparidad respecto al liberalismo que está en su base".

Con una perspectiva similar de análisis a partir de su trabajo etnográfico en Guatemala, Honduras y Nicaragua, Charles Hale $(2002,2005)$ aborda el multiculturalismo como expresión del proyecto cultural del neoliberalismo, promovido por instituciones multilaterales como el Banco Mundial y por los Estados nacionales, como una respuesta a las demandas por derechos de los pueblos indígenas "culturalmente oprimidos y excluidos". De esta manera, el "multiculturalismo neoliberal" promueve el reconocimiento proactivo de un grupo de derechos culturales en el contexto de la equidad intercultural (legislación antidiscriminación, reformas en la política educativa, reconocimiento de las lenguas indígenas, etc.) y un vigoroso rechazo del resto de derechos, provocando una dicotomía entre concesiones y prohibiciones, la cual estructura el espacio político para los activistas por los derechos indígenas al distinguir entre sujetos reconocidos y peligrosos (recalcitrantes, radicales) y establecer los límites del campo de los derechos legítimos y de las formas de alcanzarlos (Hale, 2002, p. 490).

En esta línea, se puede afirmar que el discurso del multiculturalismo, como discurso dominante y enfoque teórico político para el tratamiento "adecuado" de las diferencias y la diversidad en el marco del neoliberalismo, efectúa un triple proceso que se caracteriza por:

a. el desplazamiento de toda articulación en el abordaje de los procesos culturales con los elementos económicos, sociales y políticos, provocando una sobre-valoración de la esfera cultural en relación a las otras dimensiones de la realidad social;

b. concomitantemente, el desplazamiento de la noción de clase por la primacía de las identidades culturales o étnicas, consideradas igualmente aisladas de los procesos económicos y sociales y de sus vinculaciones con todo contenido clasista (por ejemplo las identidades étnicas resultantes pierden los contenidos vinculantes con la condición de campesinos, como si se tratara de dos realidades contrapuestas); y,

c. la reducción del horizonte de las políticas públicas que pueden ser asumidas por parte del Estado hacia los pueblos indígenas a políticas de la identidad, que suponen el reconocimiento de la diversidad en sus aspectos culturales, la concesión restringida de algunos derechos de difícil aplicación y programas de desarrollo con un corte asistencialista, destinados a paliar los efectos del modelo económico sobre las comunidades indígenas. No se considera, en este horizonte, políticas que puedan poner en riesgo el modelo de acumulación o que incidan en factores estructurales que condicionan la desigualdad económica y la dominación de los pueblos indígenas.

En suma, para concluir este acápite, el multiculturalismo como dispositivo biopolítico, al posicionarse como discurso directriz para conducir la acción del Estado frente a la cuestión étnica, permite al Estado-nación encontrar en la diversidad cultural su propio espacio de legitimación y de construcción de hegemonía. Cual vacuna contra los efectos disruptivos que representaban los levantamientos indígenas y los cuestionamientos del movimiento al sistema de dominación étnica, a los fundamentos etnocéntricos y a la naturaleza del Estado-nación, para mantener el curso del modelo neoliberal y el patrón de acumulación y reproducción capitalista (especialmente en la agricultura), con el multiculturalismo el Estado se inmuniza inyectándose una pequeña dosis de tolerancia y valoración de la diversidad cultural. De esta forma, administra y diseña políticas mediante las cuales domestica y encuadra las demandas 
étnicas en un curso asimilable por el Estado, políticas que marcan a su vez cierta continuidad con los afanes integracionistas que caracterizaron al indigenismo en América Latina. Redefine así el marco y las condiciones en las cuales "hacer vivir y dejar morir" (Foucault, 2001: 218) a las poblaciones indígenas.

Paralelamente, el dispositivo del multiculturalismo incide en el proceso de subjetivación de quienes son su objeto principal, modelando y disciplinando las conciencias y las prácticas de los indígenas como sujetos. Así, penetra en las percepciones del movimiento indígena y sus representantes enmarcando sus expectativas y reivindicaciones en el terreno de lo "políticamente correcto", lo posible y aceptable por el propio Estado, provocando una discriminación entre sujetos reconocidos y peligrosos e imponiendo una regulación moral sobre los mismos. Se trata de la construcción del "indio permitido" en la figura desarrollada por Hale (2002 y 2005). En relación al conjunto del movimiento indígena, desde sus representantes a sus bases, el dispositivo multicultural contribuye a domesticar su discurso, sus reivindicaciones y sus luchas, mediante la tendencia a culturalizarlas y vaciarlas de cualquier contenido clasista.

\section{Neodesarrollismo, construcción de hegemonía y Estado plurinacional degradado}

La llegada de Rafael Correa al gobierno se produjo en un momento en que varios países de América Latina transitaban por nuevas experiencias políticas protagonizadas por la presencia de gobiernos "progresistas" y de centro izquierda que tenían como denominador común la crítica a las políticas neoliberales aplicadas en la región, la recuperación del papel de los Estados nacionales en la economía y el fortalecimiento de los procesos de integración regional. Estos aspectos que caracterizaron el nuevo momento político de la región, contrapuesto al que primó durante la década del 90, y, la propia retórica de estos gobiernos llevaron a algunos autores a caracterizar a los mismos como postneoliberales (Martínez, 2014; Sader, 2008, Acosta, 2012). Sin embargo, esta caracterización presenta dificultades puesto que en la comprensión más común de este término subyace el equívoco de considerar al neoliberalismo apenas como una doctrina económica, una ideología o una política económica asociada a ella, basada en una oposición simplista entre el mercado y el Estado (Laval y Dardot, 2013). Ello conduce a subvalorar un conjunto de elementos de continuidad con las políticas neoliberales y perder de vista el papel actual de los Estados (con gobiernos "progresistas" o "neoliberales") en la consolidación del proceso de re-estructuración del patrón de acumulación y reproducción capitalista operado en América Latina desde los años $80^{10}$.

En este sentido, la caracterización de estos gobiernos como neodesarrollistas ${ }^{11}$ se ajusta mejor al proyecto de modernización capitalista que promueven, al mismo tiempo que, como lo anota Harvey, los Estados desarrollistas se compatibilizan con el proceso neoliberal en la medida en que facilitan la competencia, crean un clima favorable de negocios y operan conjuntamente con los intereses corporativos, con la diferencia de ser activamente intervencionistas, especialmente en la construcción de infraestructura (Harvey, 2008). A ello se debe agregar que muchas de las reformas neoliberales para favorecer las grandes inversiones y la expansión del capital permanecen intocadas y que las políticas sociales compensatorias y focalizadas aplicadas por los gobiernos "progresistas" forman parte de las recetas neoliberales.

10 Para una reflexión crítica sobre el proceso de re-estructuración productiva en América Latina y el "postneoliberalismo", como punto de llegada y consolidación de las reformas neoliberales, ver: Stolowitz, 2012. Para una caracterización del nuevo "patrón de reproducción capitalista" en América Latina ("exportador de especialización productiva") resultante de las políticas neoliberales, ver: Osorio, 2012.

11 Una discusión sobre los contenidos atribuidos al concepto de desarrollismo y su uso en el debate latinoamericano se encuentra en: Fonseca, 2014. Para este autor el núcleo común principal del uso de este concepto está constituido por tres elementos centrales: a) la existencia de un proyecto deliberado que toma como su objeto a la "Nación y su futuro"; b) "la intervención consciente y determinada del Estado" para viabilizar este proyecto; c) la industrialización, como camino buscado para acelerar el crecimiento económico y el progreso técnico, inclusive para el sector primario. Todo esto dentro de los marcos institucionales de la economía capitalista (Fonseca, 2014: 41). 
Efectivamente, al revisar el alcance de las transformaciones producidas en el Ecuador, luego de la primera fase de consolidación política del gobierno de Correa hasta la aprobación de la Constitución vigente en el año 2008, se evidencia con claridad que lo que ha estado en curso es un proyecto de modernización y expansión capitalista con un protagonismo fuerte del Estado $^{12}$, en lugar de un proceso de cambios estructurales que prefiguren un modelo distinto de desarrollo nacional con una marcada participación de los movimientos sociales. Este proyecto neodesarrollista, sustentado en una visión productivista que el gobierno actualiza permanentemente en todos los niveles de la gestión pública, en función de la lógica y el principio universal de la competencia que caracteriza la gubernamentalidad neoliberal ${ }^{13}$, puede ser definido a partir de los siguientes elementos centrales:

a. La preminencia de la matriz primario-extractiva-exportadora en la economía como base para sustentar el crecimiento económico (petróleo, megaminería, agronegocios), con participación y predominio de grandes empresas, que aprovechó el ciclo de altos precios de las materias primas y alimentos en el mercado internacional (2004-2013).

b. La renegociación de la participación del Estado bajo un discurso nacionalista en los contratos y concesiones establecidas con las empresas transnacionales para la explotación de petróleo y minería. Estos procesos de renegociación suponen mayores ingresos para el Estado, aunque mantienen las inversiones en manos de grandes corporaciones transnacionales. La promoción de la minería en gran escala y la apertura de nuevos campos para la explotación petrolera no cambia la inserción subordinada al capital transnacional global (Acosta, 2012), profundiza un modelo extractivista que atenta contra los derechos colectivos de pueblos indígenas y de campesinos asentados en esos territorios y agrava la devastación ambiental ${ }^{14}$.

c. Con ingresos fiscales favorecidos por los altos precios del petróleo durante la mayor parte de años de su gestión, la promoción de fuertes inversiones públicas especialmente en grandes obras de infraestructura como carreteras y represas hidroeléctricas, en asociación con empresas privadas. La participación del Estado en la dinámica económica estuvo acompañada de un re-diseño institucional de las entidades del Estado y del aparato burocrático con una lógica tecnocrática de gestión.

d. Paralelamente el gobierno articula su política social en torno a programas asistenciales orientados a la entrega de subsidios focalizados en paliar la pobreza (bono de desarrollo humano) e inversiones en educación y salud en porcentajes del PIB mayores que en gobiernos anteriores. Estas políticas sociales, junto con la entrega de algunas concesiones y recursos para atender demandas puntuales de algunos sectores, son operadas en alianza con líderes y autoridades locales para obtener réditos políticos y garantizar el respaldo electoral de amplias camadas de sectores populares. Estas políticas sociales no están acompañadas de medidas estructurantes que disminuyan la concentración de recursos productivos en el campo (especialmente tierra y agua) o para alterar las tasas de ganancia de las empresas en beneficio de las clases trabajadoras, propiciando una distribución efectiva de la riqueza.

12 Mario Unda (2013) subraya que el gobierno de Correa ofreció a las clases dominantes un Estado “capaz de responder a las necesidades estratégicas que se desprenden del momento particular de desarrollo del capital". Se trata de un Estado capaz de representar los intereses del conjunto del capital, de crear las condiciones para la expansión capitalista, de promover la expansión de los mercados interno y externo, de garantizar la disponibilidad de fuerza de trabajo disciplinada y de ofrecer estabilidad política con el consenso activo de los dominados (Ibíd.: 34-35).

13 Sobre la racionalidad normativa de la gubernamentalidad neoliberal que lleva a los Estados a introducir y universalizar en la economía, la sociedad y en su propio seno la lógica de la competencia y el modelo de la empresa, ver: Laval y Dardot, 2013.

14 El ejemplo más emblemático de este aspecto constituye la explotación de petróleo en el Parque Nacional Yasuní y el abandono definitivo de la Iniciativa Yasuní ITT (Ishpingo-Tambococha-Tiputini) poniendo en riesgo la supervivencia de pueblos indígenas en aislamiento voluntario (Tagaeri e Taromenani) y la biodiversidad única del Parque. 
e. Una voluntad de construcción hegemónica ${ }^{15}$ para garantizar el consentimiento de la sociedad, basada en una retórica radical que se apropia de los elementos simbólicos construidos en las luchas de los movimientos sociales contra el neoliberalismo, del movimiento indígena y de la tradición revolucionaria de la izquierda latinoamericana. Esta voluntad se construye paralelamente con el ejercicio de medidas coercitivas (directas o latentes) contra los movimientos sociales autónomos y otros sujetos que disienten y levantan acciones de resistencia, frente a las políticas del régimen. De ahí la tendencia a la criminalización de la protesta social, recurrente en los últimos años ${ }^{16}$ cuando los movimientos organizados cuestionan determinadas medidas asumidas, más aún cuando estas protestas disputan el mismo espacio simbólico discursivo del gobierno, buscando la legitimación de sus luchas frente a la sociedad.

Por otro lado, en lo que se refiere a la relación específica con el movimiento indígena, la perspectiva construida a partir de las nociones de gubernamentalidad neoliberal, biopolítica y hegemonía, igualmente permite precisamente trazar las continuidades y las inflexiones producidas en la política de administración de la población indígena, descrita anteriormente, durante los últimos años de ejercicio del gobierno de la "revolución ciudadana" de Correa. Desde mi punto de vista, lejos de marcar una ruptura radical con el dispositivo del multiculturalismo neoliberal que organizó esta política neoindigenista, el proyecto neodesarrollista de modernización capitalista del gobierno de Correa, reforzó y agudizó algunos elementos de dicha política y provocó algunas inflexiones en otros, trayendo como consecuencia la degradación de los sentidos del reconocimiento constitucional del Estado plurinacional y de otras conquistas alcanzadas por el movimiento indígena en el articulado de la Constitución (derechos colectivos, derechos de la naturaleza, soberanía alimentaria, etc.) y durante todo el proceso de movilización indígena.

En efecto, más allá de los avances alcanzados en el reconocimiento de derechos en la Constitución, en algunos temas relacionados con el establecimiento de circunscripciones territoriales indígenas o con la consulta previa respecto a los planes y la explotación de recursos naturales no renovables en los territorios indígenas, los textos constitucionales son problemáticos y subsiste la ambigüedad (Martínez, 2014), lo que inviabiliza o delimita el ejercicio de estos derechos. De otro lado, al requerirse la emisión de legislación secundaria para que el articulado constitucional y los derechos establecidos tengan una aplicabilidad concreta, en todos los temas críticos para las organizaciones indígenas y su supervivencia como pueblos (minería, tierras, aguas, circunscripciones territoriales indígenas, soberanía alimentaria, autonomía política y organizativa, educación intercultural bilingüe, justicia indígena) la legislación secundaria emitida en los años posteriores ha bloqueado sistemáticamente la posibilidad de concretar los avances alcanzados en los textos constitucionales y ha desactivado su potencial transformador o contestatario frente al proceso de expansión capitalista en el campo y la matriz extractivista referida anteriormente.

Luego del reconocimiento constitucional del Estado Plurinacional en el 2008, con el proyecto neodesarrollista asumido por el Estado ecuatoriano se abrieron nuevos escenarios de conflicto entre el Estado y el movimiento indígena, en los cuales el Estado despliega una

15 A partir de una lectura de mayor aliento del proceso ecuatoriano se puede afirmar que el proceso político desplegado en el gobierno de Correa permitió la recomposición de la hegemonía burguesa en el Ecuador, al garantizar mejores condiciones para la acumulación capitalista en los distintos sectores económicos, marcar una dirección para el conjunto de la sociedad y producir y organizar el consenso de vastos sectores de la población. Esta recomposición hegemónica empieza a ser cuestionada con el advenimiento de la crisis económica provocada a raíz de la caída de los precios de las materias primas en los mercados internacionales, particularmente el petróleo, acentuada desde el año 2014.

16 Sobre la tendencia a la criminalización de la protesta social en el gobierno de Correa ver el informe de la Defensoría del Pueblo sobre la "criminalización a defensores de derechos humanos y de la naturaleza en Ecuador" (Defensoría del Pueblo, 2011) y el informe de Amnistía Internacional (2012) sobre la criminalización del derecho a la protesta en Ecuador, en que se documenta en detalle esta tendencia. 
versión renovada de una política indigenista integradora que niega protagonismo político a las principales organizaciones indígenas y transforma a las comunidades en meros receptores de la acción de gobierno y en sujetos obedientes (Martínez, 2014). En ella se instrumentaliza las nociones de plurinacionalidad e interculturalidad a los requerimientos del modelo de desarrollo capitalista, reduciéndola y degradándola al suprimir mediante la legislación secundaria cualquier vestigio de autonomía y autodeterminación indígena en las mismas.

En este sentido, ha primado una concepción instrumental y estrecha del Estado plurinacional por parte del gobierno de Correa en su discurso y prácticas concretas en las relaciones con el movimiento indígena en sus distintas expresiones. Esta concepción degradada de los sentidos de la plurinacionalidad se ha evidenciado en el tratamiento dado a la justicia indígena subordinándola a la justicia ordinaria, en los límites de los procesos de participación de las organizaciones campesinas e indígenas en la discusión de las propuestas de ley de aguas y de tierras $^{17}$, en el debilitamiento y eliminación de la autonomía del CODENPE y del Sistema de Educación Intercultural Bilingüe ${ }^{18}$ (que ha incluido el cierre de escuelas en las comunidades) y en la eliminación de la participación y control que las organizaciones indígenas ejercían en las entidades estatales indígenas. Esta concepción profundiza el dispositivo del multiculturalismo neoliberal al restringir aún más y encuadrar el alcance de los derechos aceptables por el Estado y bloquear aquellos que pudiesen colocar en riesgo el modelo económico de desarrollo.

Por otro lado, este reconocimiento restringido de derechos se realiza acompañado de políticas que afectan directamente las condiciones de reproducción social de las comunidades y favorecen las dinámicas de acumulación capitalista a costa de la espoliación de los recursos de sus territorios cuando ellos son de interés para el capital. A ello se agrega el despliegue de políticas agrarias enfocadas en el mejoramiento de la productividad y en favorecer los encadenamientos productivos y la integración vertical campesina indígena por medio de la agricultura de contrato, que fundamentalmente refuerzan las condiciones de subordinación y explotación campesina por los agronegocios, alejándose de la perspectiva de la soberanía alimentaria y la agroecología reivindicada por las organizaciones campesinas e indígenas.

A ello se agrega la respuesta confrontadora generada por el gobierno frente a las movilizaciones indígenas y cuestionamientos levantados por los dirigentes indígenas, convocando contramarchas, usando la represión policial y criminalizando las protestas por la vía judicial bajo la acusación de sabotaje y terrorismo contra los dirigentes. En adición, levantó campañas mediáticas de descalificación de las dirigencias indígenas y de las posiciones asumidas por sus organizaciones, mientras paralelamente se instrumentalizaban otras organizaciones afines al gobierno por medio de la entrega de recursos para la atención de demandas puntuales y se usaba la influencia de funcionarios, autoridades y "representantes" indígenas afines al gobierno. Se trata de una política sistemática de intervención, control y desestructuración sobre las organizaciones autónomas y de descalificación de sus dirigentes delante de la sociedad. Esta política coercitiva, recrea y profundiza la referida figura del "indio permitido" desarrollada por Hale (2002 y 2005) en contraposición a aquellos sujetos considerados "recalcitrantes", "peligrosos" o "tirapiedras" quienes son estigmatizados, contribuyendo así, como subraya Martínez (2014), al resurgimiento en la sociedad de prejuicios racistas e inclusive de la violencia contra los indígenas.

17 La elaboración de propuestas tendientes a propiciar la desconcentración y distribución de la tierra y el agua han formado parte de los esfuerzos y luchas levantadas por las organizaciones indígenas. Estas propuestas no tuvieron eco en el gobierno y en el caso de la propuesta de ley de tierras presentada por las organizaciones, frente a la oposición levantada por los empresarios agrícolas a cualquier proyecto de esta índole, la posición del presidente Correa fue explícita para bloquear estas iniciativas (Hidalgo, 2013). La ley de tierras recientemente aprobada muestra precisamente que nunca estuvo en el horizonte del gobierno una ley que efectivamente promueva la redistribución de la tierra y abra un frente que confronte a la burguesía agraria en el campo y cuestione el patrón de acumulación capitalista bajo el dominio del agronegocio.

18 Para mayor detalle de los cambios políticos y legales producidos en el Sistema de Educación Intercultural Bilingüe, ver: Martínez, 2014. 


\section{Bibliografía}

Acosta, Alberto. 2012, "El Retorno del Estado, primeros pasos postneoliberales, mas no postcapitalistas", en: Revista La Tendencia, número 13, FES - ILDIS, Quito, pp. 62-72.

Amnistía Internacional. 2012, "Para que nadie reclame nada” ¿Criminalización del derecho a la protesta en Ecuador?, EDAI, Madrid.

Bretón, Víctor. 2009, "La deriva identitaria del movimiento indígena en los Andes ecuatorianos o los límites de la etnofagia", en: Martínez, Carmen (Comp.) Repensando los movimientos indígenas, FLACSO, Quito, pp. 69-121.

Cervone, Emma. 2009, "Los desafíos del multiculturalismo", en Martínez, Carmen (Comp.). Repensando los movimientos indígenas, FLACSO, Quito, pp.199-214.

DEFENSORIA DEL PUEBLO DE ECUADOR. 2011, Los escenarios de la criminalización a defensores de Derechos Humanos y de la Naturaleza en Ecuador: Desafios para un Estado Constitucional de Derechos, DPE, Quito.

Díaz-Polanco, Héctor. 2009, Elogio de la diversidad: Globalización, multiculturalismo y etnofagia, Monte Avila Editores latinoamericana, Caracas.

Duménil, Gérard y Dominique Lévy. 2014, A crise do neoliberalismo, Boitempo, Sao Paulo.

Esposito, Roberto. 2006, Bíos: Biopolítica y filosofia, Amorrortu Editores, Buenos Aires-Madrid.

Fonseca, Pedro. 2014, "Desenvolvimentismo: A construção do conceito", en: Bojikian Calixtre, André Martins e Marcos Macedo (Eds.), Presente e futuro do desenvolvimento brasileiro, IPEA, Brasilia.

Foucault, Michel. 2011, “1976 -O Discurso Não Deve Ser Considerado Como ...”, en: Foucault, Michel. Arte, Epistemologia, Filosofia e História da Medicina, Coleção Ditos \& Escritos, Vol VII, Editora Forense Universitária, Rio de Janeiro.

2006, Seguridad, territorio, población, Fondo de Cultura Económica, Buenos Aires.

2005, El orden del discurso, Tusquets Editores, Buenos Aires.

2001, Defender la sociedad, Fondo de Cultura Económica, Buenos Aires.

1979, La arqueología del saber. 6a. Edición, Siglo XXI Editores, México.

Fraser, Nancy. 2007, “Reconhecimento sem ética?”, en: Souza, J. y P. Mattos (Org.), Teoria crítica no século XXI, Ed. Annablume, São Paulo, pp. 113-139.

2001, "Da redistribuição ao reconhecimento? Dilemas da justiça na era pós-socialista", en: Souza, Jessé (Org.), Democracia hoje: novos desafios para a teoria democrática contemporânea, Ed. UNB, Brasília, pp.245282.

2000, "Rethinking Recognition", en: New Left Review, n 3, May-june, London, pp. 107-120.

Guerrero, Andrés. 2010, Administración de poblaciones, ventriloquía y transescritura, IEP, FLACSO Ecuador, Lima.

2000, "El proceso de identificación: sentido común ciudadano, ventriloquia y transescritura", en: Guerrero, Andrés (Comp.), Etnicidades, FLACSO - ILDIS, Quito, pp. 9-60.

Gramsci, Antonio. 2002, Cadernos do Cárcere. Volume 5, Editora Civilização Brasileira, Rio de Janeiro.

2000, Cadernos do Cárcere, Volume 3, Editora Civilização Brasileira, Rio de Janeiro.

Hale, Charles. 2002, "Does Multiculturalism Menace? Governance, Cultural Rights and the Politics of Identity in Guatemala", en: Journal of Latin American Studies, Vol 34, No. 3, pp. 485-524.

2005, "Neoliberal Multiculturalism: The Remaking of Cultural Rights and Racial Dominance in Central America", en: Political and Legal Anthropology Review Vol. 28 No.1, pp.10-28.

Harvey, David. 2008, O Neoliberalismo. História e Implicações, Ediciones Loyola, São Paulo.

Hidalgo, Francisco. 2013, "El jaguar desdentado: Propiedad agraria y subordinación”, en: Alvarez Freddy, et al., El Correísmo al desnudo, Montecristi Vive, Quito, pp. 161-164.

Honneth, Axel. 2007, "Reconhecimento ou redistribuição? A mudança de perspectivas na ordem moral da sociedade", en: Souza, J. y P. Mattos (org.), Teoria crítica no século XXI, Ed. Annablume, São Paulo, pp. 79-93.

2003, Lutas por reconhecimento: a gramática moral dos conflitos sociais, Ed. 34, São Paulo.

Kymlicka, Will. 1996, Ciudadanía multicultural: Una teoría liberal de los derechos de las minorías, Paidós, Barcelona - Buenos Aires - México.

Laval, Christian y Pierre Dardot. 2013, La nueva razón del mundo. Ensayo sobre la sociedad neoliberal, GEDISA, Barcelona. 
Martínez, Luciano. 2005, "El movimiento indígena ecuatoriano en la encrucijada", en: Revista ALASRU Nueva Época, Análisis latinoamericano del medio rural. Universidad Autónoma de Chapingo, Chapingo, Número 2 pp. 121-142.

Martínez, Carmen. 2014, "Managing Diversity in Postneoliberal Ecuador", en: The Journal of Latin American and Caribbean Anthropology, Vol. 19, No. 1, pp. 103-125.

Mattos, Patrícia. 2006, A sociologia política do reconhecimento, Ed. Annablume, São Paulo.

Osorio, Jaime. 2012, “América Latina bajo el fuego de las grandes transformaciones económicas y políticas”, en: Política y Cultura, primavera 2012, núm. 37, pp. 65-84.

Sader, Emir. 2008, Refundar el Estado. Posneoliberalismo en América Latina, CTA - CLACSO, Buenos Aires.

Stolowicz, Beatriz. 2012, A Contracorriente de la hegemonía conservadora, Espacio crítico - ITACA - UAM Xochimilco, México.

Taylor, Charles. 2009, El multiculturalismo y "la política del reconocimiento". 2a Ed., Fondo de Cultura Económica, México, 2009.

Unda, Mario. 2013, "Modernización del capitalismo y reforma del Estado", en: Álvarez Freddy et al., El Correísmo al desnudo, Montecristi Vive, Quito, pp. 33-38.

Žižek, Slavoj. 2005, "Multiculturalismo o la lógica cultural del capitalismo multinacional”, en: Jameson, Frederic y Slavoj Žižek, Estudios Culturales. Reflexiones sobre el multiculturalismo, Paidós, Buenos Aires, pp. 137188. 